\title{
Tirawis: The Dialect and The Society In Tirat Haifa (Palestine) Prior to 1948
}

\author{
Mahmoud El Salman \\ King Faisal University, Saudi Arabia \\ E-mail: el_salman@hotmail.com
}

Received: 09-01-2016

Published: 01-07-2016
Accepted: 26-03-2016

doi:10.7575/aiac.ijalel.v.5n.4p.5
Advance Access Published: May 2016

URL: http://dx.doi.org/10.7575/aiac.ijalel.v.5n.4p.5

\begin{abstract}
This is a sociolinguistic study that peers into the strong relation between the social and cultural nature of the Tirawi dialect, and the preserving of their dialect, and the preservation of some names and naming of people and other stuff. The study shows that the distinctiveness of the Tirawi society, socially and culturally, is reflected in a sense of peculiarity in their dialect. Prior to 1948 , the Tirawi society was a closed and conservative society where belonging to the Tirawi community requires preserving their dialect, following their way of naming their children and the aliases they use within their society. Linguistically, both females and males behaved similarly in that they categorically preserved the [q] variant. As a result the key feature [q] became indissolubly linked with the Tirawis. It has become an identity feature for a Tirawi whether he or she uses it or not. In addition, the dialect became distinguished from the rest of the dialect in the area not only in its having the /q/ variant in its phonetic inventory, but also this dialect became distinguished even in the way the people of Tirat Haifa name some stuff and some proper names. Thus, to be recognized as "a real Tirawi", the /q/ variant is to appear in your dialect, in addition to the use of some family names or special way in naming other stuff such as "dress", surnames, and many other examples.
\end{abstract}

Keywords: Hypercorrection, Domain, Speech Community, Linguistic Variation 1. Introduction

The people of Tirat Haifa were forced out of their homes in 1948, as a result of the Arab-Israeli war. The way of life of the people of Tirat Haifa (Palestine, henceforth Tirawis) prior to 1948 is taken from two sources. The first was a book written about the people of this village in 1908 by Graf Mulinen. The Second was written by the author of this article in 1990 depending on the oral history. Moreover, other people were interviewed recently for the purpose of this study. The book of the author of this article "Tirat Haifa between 1900-1948" was the first book to be written about the village in Arabic. Mulinen was able to live among the people of this village, and ethnographically recorded the information about them-which is a very great advantage. I was able, as a result of meeting many people from this village who lived there and were mature enough at that time, to collect valuable information about it. Some of those whom I met in 1990 were in their $60 \mathrm{~s}, 70 \mathrm{~s}, 80 \mathrm{~s}$, or even $90 \mathrm{~s}$ at that time when I interviewed them. This means that they were in their $20 \mathrm{~s}, 30 \mathrm{~s}, 40 \mathrm{~s}$ or 50s when they were living in the village. All of them were Tirawi dialect preservers. All of them were mature enough at the time when they lived in the village, so, they remember the smallest details of how life was in the village. This is mentioned in order to confirm the reliability of the data collected for the purpose of this study. The information that I managed to collect from them led me to two major findings: 1- their genuine and natural dialects, as the interviews were not about the dialect, and as such, I succeeded in collecting natural linguistic elements indirectly. 2- The details about their social life, and thus. This enhances my ability to correlate the social and the linguistic characteristics. Meeting them so early gave me the advantage of interviewing good informants, the informants who witnessed the real life of Tirat Haifa, and still in their habits, customs and way of life very Tirawis. The interviews with those people also gave me the opportunity to be able to compare between what they said and what Mulinen said about them. Some of what Mulinen said about them, I again heard it from the native residents of the village. I also found out that some of what he said was not accurate and needs to be re-evaluated and corrected. In my attempt to make a real time study at that time, and, accordingly, I tried to interview the same informants in 2002. I found out that most of them died, or in an age that does not help me to interview them in the way that I did before. Though the situation was hurtful and painful, I found out again the importance and the advantage of interviewing those people in 1990. Twenty years were able to change the scene and made what was possible impossible.

\section{Methodology}

My study is empirical in its methods and fully dependent on naturalistic speech. All the interviews, which were conducted in Irbid (Jordan), were made using the face-to-face technique for obtaining data with regard to linguistic variation. The study comprises Tirawis, who are originally from Tirat Haifa. The size of the sample is acceptable and similar to the number of informants in many similar studies, for example the number of informants in Trudgill's (1974) study was 60 in a city with a population of 118, 610, and the number of informants in Daher's study (1998) conducted in Damascus, was 46. Labov also notes that "the structure of social and stylistic variation of language can be studied 
through samples considerably smaller than those required for the study of other forms of social behaviour" (Labov, 1966: 638). My large social network enabled me to draw my sample from both sexes.

This study is conducted in light of the Labovian Paradigm. The interviews were carried out in shops, offices, houses, and workshops. This was determined by the possible availability of the informants. The social network framework was followed and the informants were approached in the capacity of "a friend of a friend" or in some cases "a friend of a friend of a friend" (Milroy and Milroy, 1978). I also recorded some group conversations between Tirawis where this was possible. The recorded conversations could be considered "a supplementary check on these face-to face taperecorded interviews" (Labov, 1972b: 13).

The questions asked in the interviews were designed to provide a challenge for the interviewees' memories in that they depended solely on the personal knowledge of the Tirawis, and dealt with what they still remembered about the village or remembered hearing from their parents. I believe that the interviewees' attempts to prove that they remembered more about the village than anyone else reduced the attention paid to the linguistic terms used to describe the reminiscences. This, I believe, succeeded in helping me "solve the Observer's Paradox, and reduce attention paid to language" (Labov, 2001: 36). So, I can claim that at least in most parts of the interviews I succeeded in knowing "how [Tirawis] talk when they are not being systematically observed" (Labov, 1972a: 181). Nevertheless, I also discovered that the 'Observer's Paradox' appeared to be difficult to be solved at least at the beginning of the interviews. Indeed, the interviewees' attempts to make their speech conform to Standard Arabic are clearly seen at the beginning of many of the interviews. I also asked additional questions after the end of the main interview. These questions were designed to measure informants' perception of different variants in the speech of Tirawis.

I divided the sample into two kinds of groups, according to sex, and age. In order to gain a statistically accurate view of the use of the variables a univariate analysis is employed. For the purpose of using the univariate analysis each group is presented as a number.. The male group is given number 1 and female group number 2 . The young age group is 1 , the middle age group is 2 , and the old 3 . The uneducated group is presented as number 1 and the educated group as number 2. The items that are used to be Tirawi old items are presented as (OTI). These items include the words that are classified as peculiar to Tirawi dialect. In our study they are: fistyyan "dress", Khwayyah, "a name of breakfast meal", daar "to mean surname in Old Tirawi dialect",. New synonyms to these words and used by new generations are presented as (NTI). The use of [q] in the table is presented as [QU], where U stands for use, while the use of any other variant rather than the $[\mathrm{q}]$ is presented as [QD], where D stands for disuse. The use of old Tirawi items is presented as [OTIU], where u stands for use, and the [OTID], where D stands for disuse.

\section{The Linguistic and Social Situation}

Tirat Haifa is distinguished linguistically from the rest of the adjacent villages in its dialect. While most of the dialects in the rural areas in Palestine, has the velar / $\mathrm{k} /$ variant of the (Q) variable (see also (Abdel-Jawad, 1981, Al Khatib, 1988, Ammara et al, 1991), the dialect of Tirat Haifa has the uvular /q/ variant in its phonetic inventory. The /q/ variant is associated with the people of Tirat Haifa and The voiceless uvular stop [q] is the key feature of the Tirawi dialect (henceforth TD), and as a result it became an identity of the Tirawi people. For example, The major external and economic relations of the people of this village were with the nearest city, Haifa. The key feature of the dialect of alTira, namely, the voiceless uvular stop [q], and the key feature of the dialect of Haifa, namely the glottal stop [?], were the point around which most linguistically oriented anecdotes clustered. The social meanings of these linguistic features came to be manipulated by both the people of al Tira and these of Haifa, to describe one another. As a result of its being considered as an identity for Tirawis. the key feature of al Tira, namely the [q] variant, used to be used by the people of Haifa humorously to describe the stubbornness and toughness of the Tirawis. For instance, if a man from Haifa wanted to know if somebody was from al Tira he might humorously ask him: /inta min illi qawwasu ilbahar/ 'Are you one of those who shot the sea/'. And if the answer was yes, it was not uncommon for this question to be followed by a second typical question: /qarqa babuur ittiirih willa bałduh/ 'Has the grinding-machine of al Tira started making a noise or not yet?' Notice the necessity of the appearance of the key feature [q] of this dialect in these phrases so as to convey this humorous and friendly social meaning. The word /qarqą/ 'made a grinding noise' has the [q] variant twice confirming the speaker's intention to signal the correlation between one's being a Tirawi and one's being a user of [q].

My point in this discussion is to show that the key feature [q] became indissolubly linked with the Tirawis. It has become an identity feature for a Tirawi whether he or she uses it or not. Most Tirawis who still preserve the local [q] variant are illiterate. Figure (1) shows this. It shows that the [q] was used the most by those who are classified as uneducated (number 1 presents this). The [q] used in my study indicates one's being a Tirawi and is not correlated to level of education as mentioned in most of the studies in the Arab world (see for example, Abdel Jawad, 1981; Al Khatib, 1988; Kanakri, 1988; AL-Wer, 1991, 1999, 2000; Walter, 1991; Daher, 1998; Amara et al, 1999). In addition, the [q] was used by them in words that are not calssifed as SA words (see also Al Khatib, 1988, kanakrih, 1988). The following traditional Tirawi song (which also could be considered word play game) shows the use of the [q] in words that are considered part of the Tirawi vernacular but not part of SA (Standard Arabic or even MSA (modern Standard Arabic). It is also worth noticing with this regard, that the $/ q /$ is part of every word used in the song. Other word such as khayya (my brother) is also peculiar to Tirawi dialect and it is used in the song. What is also noticed in the song is the repetition of the word qalo (he told him), and qalo malak (he replied what happened) whih are two phrases preceded any sentence uttered by old Tirawis while narrating a story. In addition, the female name nabbiha, which is a classical Tirawi name, is also used: 
-Qalo khayya

-qalo malak

-qalo nabbyha

-qalo malha

Qalo matat

Qalo walah

Qalo ah inchalh thaqha

-he said oh my brother

-he replied what happened to you

-he said Nabyha ( a a name of a girl)

-he said what about her

-he said she died

-he replied do you swear?

-he said yes, I wish you will follow her (saying that as a joke).

Even the Tirawis who were born in Jordan and their dialect is not Tirawi dialect, they sing this song using the [q] variant, and the other Tirawi words such as khayyah. So the aim of showing Tirawi idnitity and origin is what is sought by any Tirawi when they sing such a song.

Estimated Marginal Means of $Q$

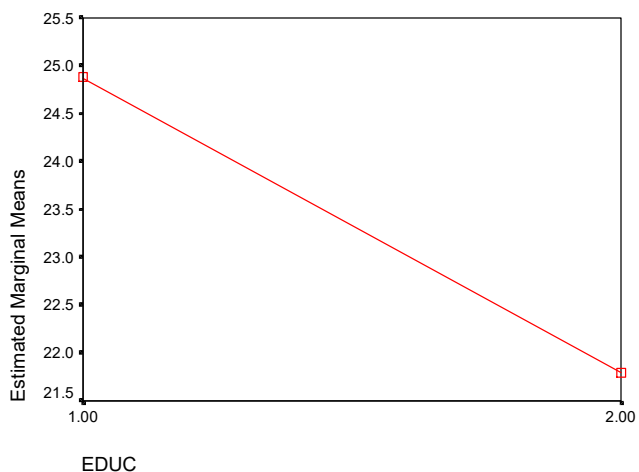

Figure 1

\section{Lexical Items}

In Tirat Haifa, there are some lexical items that were used to mean something different from that found in many Arabic societies.

For example, In Tirat Haifa the word "daar" (house) was used to mean family, or tribe or clan. For instance, clans or families like 1- Ammora family, or 2-El Salman family, or 3-Hajiir, were named as:

1-Daar Ammora (meaning all of the people who belong to this group (Ammora), and, thus, their surname is Ammora)

2-Daar El Salman (meaning all of the people who belong to El Salman group, and thus, their surname is El Salman.

3- Daar Hajiir (meaning all of the people who belong to the group called (Hajiir)

See also Mullinin (1908) as he mentioned the names of all of the families of Tirat Haifa at that time, and he used the name "Daar" to indicate families. It seems that he cited the word as it is used by the people of Tirat Haifa at that time. Mullinen also indicated the fact that one of his informants was Mahmoud Al Badawi. He also used his picture to be the cover of the book. It is worth mentioning that Al Badawi is from my own group, Al Hamola. People of Tirat Haifa in general, and, in particular Al Hamola, still use the word "Daar" to mean family. In Jordan, the word clan or tribe is used to mean a group of people who belong to the same root (to the same big family). As the word Daar is not understood to mean clan or any group of people who belong to the same root in Jordan, people of Tirat Haifa do not use the word "Daar" to mean family or clan any more, when the interlocutor is not Tirawi. Indeed, it was found out that $90 \%$ of the youth do not recognize that the word "Daar" was used to mean family. This, as a result, indicates a linguistic change among Tirawi new generations with regard to some lexical items.

Daar does not have a plural when it means families.

The word "Daar" was used to mean family, as each group used to live in a certain area together. Though the different families of the same group lived in different "daars" (houses) in the same area, together they lived in the same area, so 
as if they lived in a big "daar" containing all these small doors (houses). As a result, the word "daar" started to be used to mean all of the people who live in a given area and normally belong to the same group. Notice, for example, that the whole village was divided into two parts. One of them is called Al Hara Alqblyyah (the southern neighbourhood.), and the other is called al Hara alshamallyah (the northern neighbourhood). There is a group of doors (houses) in each neighbourhood that belong to people who are relatives and descend from the same origin.

Unlike most of the Arab world, the people of Tirat Haifa used to pronounce the word Fostaan /fistyaan/ "dress". Some old Tirawis argued that the word fistyyan differs from the word Fostaan, as the word fistyyan means the traditional Tirawi female dress in particular, but not any other female dress in the area. Most of the villages that are adjacent to Tirat Haifa, namely, Ossfyyah, Ayyan Houd, Ijzim, have almost the same type of female traditional dress. Nonetheless, the word Fosttan is used but not the Tirawi word fistyyan. This confirms the peculiarity of the word to Tirawi dialect but not the peculiarity of that traditional dress to Tirawi society.

The word miqqthah "farm", is also distinctive to the Tirawi dialect. Most of the people say mazra3ah "farm" but never miqthah.

Even some names of some traditional food are known only in Tirat Haifa and they were not found to be used in any other place, including the adjacent villages of Tirat Haifa. One of these traditional dishes that is used to be the dish at the time of fatoor (breakfast), is named Ikhwayyah. Ikhwayyah is a dish that is prepared from grilled bread and cinnamon. They boil the cinnamon with water in a big pot as if they were making tea. Then they put the boiled cinnamon (called ainnar when cinnamon is boiled with water and prepared in this way) on the grilled bread. Thus, when the boiled cinnamon is mixed with the bread, it then becomes akhwayyah.

The word khayya "my brother", and the word khayyta, "my sister", are distinctive to Tirawi dialect. The emphatic glide in the word, together with a long vowel word-finally renders this word very Tirawi.

In our attempt to find out the reason that leads Tirawi dialect to have some lexical items that are exclusively used by only Tirawis, we find that the nature of the Tirawi society plays the major role in that. Tirat Haifa is one of the biggest villages in the northern coast of Palestine. The people of it are known to be proud of being Tirawi. Prior to 1948, AlTira was linked to Haifa by a spur to a coastal highway northwest of the village. Al-Tira was one of the most important villages in the Haifa district; it was the district's most populous village and the second largest (after Ijzim) in area (Khalidi et al, 1992: 195). The competition between Tirawis as rural people, and the people of Haifa as the people of the urban center, leads Tirawis to criticize any Tirawi who tries to abandon the Tirawi dialect in favour of the posh Haifian dialect. That was considered an attempt to disassociate oneself from the Tirawi group, something which everybody avoids to do. Words that are obviously known to be very Tirawi, and are exclusively used by them such as: fistyyan, Miqthah, and khwaayyah, and are considered markers in their dialect, are avoided the most to be abandoned. As the Tirawi dialect is one of the very few dialects in the area whose phonetic inventory has the [q] variant of the (Q) variable, this dialect became very important as a marker and a feature of being Tirawi. These factors, as a result, play the major role in preserving such very Tirawi words. In addition to this, Tirawis in Tirat Haifa dealt with one another as close relatives even if they belong to different families. In Haifa, for example, Tirawis from all families used to sit in the same qahwa (café). And if a Tirawi faces a problem with any one else in Haifa (even if he was involved in a fight with somebody else), other Tirawis would support him as a result of their belonging to the Tirawi "tribe". This strong feeling of belonging to the Tirawi group, regardless of the surname they have, made many Tirawis use the proper name "Tirawi" as a surname when they are out of the village and wish to identify themselves. In the village, they identify themselves by their first name in addition to the family name or the first name in addition to the father's name being preceded by the definite article al "the". But when they are out of the boarders of the village, they identify themselves using the first name and the word Tirawi, as a proper name. So to be a Tirawi is not something that one can simply be, but it is something that requires adopting some habits and beliefs, in order to meet the criteria of being a Tirawi. Though kinship is important, it is in no means enough to render you a "genuine Tirawi" without acting the way Tirawis act. Using the Tirawi key feature, namely the /q/ sound, being ready to stand by a fellow Tirawi in any conflict, and preferring to marry your daughters only to Tirawis, can only help you associate yourself to the Tirawi group.

This strong relation between the members of the Tirawi group leads to enhance their adhering to whatever is considered Tirawi, including their dialect, habits and culture. For example, a Tirawi feels proud when all of his daughters are married only to other Tirawis.

When a Tirawi meets another Tirawi in any domain outside of the village, he greets him saying "kiifak qarabti, "how are you my relative" even if both of them belong to different Tirawi families. Notice the importance of pronouncing the word qarabiti, "my relative" in Tirawi dialect, to enhance this identity-being Tirawi, through the use of the key feature of the Tirawi dialect, namely the uvular/q/ sound, with the word qarabti.

\section{Names of People}

Like most Arabs, Tirawis reckon kinship through the male line. The name of the male is important and it is not uncommon to find that most of Tirawis name their sons after the names of their fathers. For example, if the name of the man is Ali, and his father's name is Salim, it is normal that that man names his son Salim, after his father's name. So the name of the son becomes: Salim Ali Salim. However, if the man dies while his wife is pregnant, it is normal also to find that the son is named after the name of the father himself. So the name became Ali Ali.

In Tirat Haifa itself, it is very rare to use the surname (the family name) when one wants to identify someone within the same group. This is due to the fact that within the same group we might have many persons who have the same first 
name and at the same time they all carry the same surname. So Tirawis used to identify people inside the Tirat Haifa domain by mentioning the first name in addition to the father's name being followed by the definite article al (the). So they say Mohammed Al Fahid, meaning Mohammed who is the son of Fahid.

Though what have been mentioned might be found in another area, what is distinctive for Tirawis is when the father dies or a divorce takes place while his children are still in an early age, the mother takes the role of the father. As a result, Tirawis used to call the children using their mothers' names informally as surnames. So a successful man might be called: Khalid al Fatimah. In this case, it would be understood in Tirat Haifa that the case is so; they are the children of their mother, who helped them grow up, but not their father. Many examples are still found among Tirawis of today.

\section{Findings and discussion}

Table (1) shows the distribution of the interviewees by sex and place of birth. The sample has only members who are old and were born in Tirat Haifa and Tirawis who were born in Jordan.

Table 1. Distribution of informants by sex and place of birth

\begin{tabular}{lccc}
\hline \multicolumn{1}{c}{ Sex } & M & F & Total \\
Age & & & \\
\hline Young & 8 & 8 & 16 \\
Middle & 8 & 8 & 16 \\
Old & 8 & 8 & 16 \\
\hline Total & 24 & 24 & 48 \\
\hline
\end{tabular}

\subsection{Tirawi dialect preservers}

Table 2. The distribution of the variable (OTI) by age and sex

\begin{tabular}{|c|c|c|c|c|c|}
\hline Sex & \multicolumn{2}{|c|}{$\mathrm{M}$} & \multicolumn{2}{|c|}{$\mathrm{F}$} & \\
\hline Age & $\begin{array}{c}\text { [OTIU] } \\
\%\end{array}$ & $\begin{array}{c}\text { [OTID] } \\
\%\end{array}$ & $\begin{array}{c}\text { [OTIU] } \\
\%\end{array}$ & $\begin{array}{c}\text { [OTID] } \\
\%\end{array}$ & [ \\
\hline Young & 0 & 100 & 0 & 100 & \\
\hline Middle & 15 & 85 & 10 & 90 & \\
\hline Old & 100 & 0 & 100 & 0 & \\
\hline
\end{tabular}

Table 3. The distribution of the variable (Q) by age and sex

\begin{tabular}{ccccc}
\hline Sex & \multicolumn{2}{c}{$\mathrm{M}$} \\
\hline Age & {$[\mathrm{qu}] \%$} & {$[\mathrm{qd}] \%$} & {$[\mathrm{qu}] \%$} & {[]$\%$} \\
\hline Young & 2 & 98 & 3 & 2 \\
Middle & 10 & 90 & 6 & 0 \\
Old & 100 & 0 & 98 & 0 \\
\hline
\end{tabular}

Table (2) shows that the OTI are categorically used by old Tirawi. Males and females categorically used them. The rate reaches $100 \%$ by both males and females. The use of the old dialect increase as one scans down the column in the table. The table also shows that (OTI) completely disappear in the speech of the young, and it is used in a very low percnatge in the speech of the middle age members.. Table (3) shows that the [q] variant is used in 100\% among old males and females of the total number of occurrences of the (Q) variable. SPSS statistical analysis also shows that age is very significant in the use of OTI. ( $\mathrm{P}<.05$ while $\mathrm{P}<000$ for age with regard to the use of the [OTI]). SPSS statistical analysis also shows that age is very significant in the use of the $[\mathrm{q}]$ variant. $(\mathrm{P}<.05$ while $\mathrm{P}<000$ for age with regard to the use of the $[\mathrm{q}])$.

Linguistically, both females and males of the old age group behaved similarly in that they categorically preserved the old Tirawi dialect, namely the [q] variant and the (OTI). SPSS analysis shows that sex, by contrast, has a very low significance in the use of the [q] variant $(\mathrm{P}<.05$ while $\mathrm{P}<.278$ for sex in the use of the [q] variant). The crucial factor, therefore, is age. It is a very well known fact that the old are subject to much more pressure from their society to preserve their native dialect than the young (Al-Wer, 1991; 91; Walter, 1991: 201). Eckert also reports that "community studies of variation frequently show that increasing age correlates with increasing conservatism in speech" (Eckert, 1997: 157). Linguistic variation was witnessed in the area. For example, the [k] variant was used in the villages that are adjacent to Tirat Haifa before 1948, such as Ijzim, 3ayn Hawth. The glottal stop [?] variant was used in Haifa. The word 
fostan (dress), or 3ailah (family), were used in these areas, but not the Tirawi sounds or lexical items. Nonetheless the Tirawis show preservation to this dialect even when they settled in Jordan. This can inform us about the strong effect of the Tirawi society on them to do so. The use of this original dialect is used to achieve something beyond any linguistic aim. It aims to confirm identity, and as such helps the user of this native dialect to project himself as part of Tirawi society. In other words, appearing as "real Tirawi". Abandoning this dialect is equal to abandoning one's identity. Even the young of today, and who were born in Jordan, once they want to appear as "real Tirawis", in any Tirawi gathering, the use of these old words is seen to be the best and the fastest way to prove so. So rendering oneself real Tirawi requires the emergence of these words in the speech and the suppression of any other words from any other dialect. A high degree of Tirawi dialect is closely linked with strong resistance to any other identity rather than the Tirawi's. as such it could be said that the social meanings of the use of the Tirawi dialect "hop" from Tirat Haifa to Jordan. In other words, younger generations do not and could not master the Old Tirawi dialect. Nevertheless, they are well aware of its social meanings. It is noticed for example, that words, like daar, to mean family, is deliberately used by some young Tirawis within the Tirawi domain. The aim of using this linguistic tool to achieve something social was also very obvious. The social meanings that some Tirawi words have is not aware by the larger speech community in Jordan. The social meanings of these words are well aware of by Tirawis. Thus, the hypothesis suggests itself. Within any Tirawi domain, say Tirawi houses, Tirat Haifa family Dywan (the court of Tirat Haifa families), Tirawi wedding parties, the use of some Tirawi words that reflect intimacy and solidiraty among the group, increases. Though these words are not part of the linguistic competence of some of the speakers, the deliberate use of them is easily noticed this is what Mesthrei et al call "hypercorrection". In thses Tirawi domains younger generations exaggerate in the use of the native dialect as a result of "their tendancy to use the pronunciation considered correct and appropriate" (Mesthrie, et al, 2000). Table (4) shows this. The use of the (OTI) noticeably increases in the speech of the young as well as the middle aged group. The use of the (OTI) in the speech of the old stays high and almost in the same percentage, as their use of the native dialect is natural whether they are being observed or evaluated, or not.

Table 4. The distribution of the variable (OTI) by age and sex

\begin{tabular}{|c|c|c|c|c|c|c|}
\hline Sex & \multicolumn{2}{|c|}{ M } & \multicolumn{4}{|c|}{$\mathrm{F}$} \\
\hline Age & $\begin{array}{c}\text { [OTIU] } \\
\%\end{array}$ & $\begin{array}{c}\text { [OTID] } \\
\%\end{array}$ & {[} & $\begin{array}{c}\text { [OTIU] } \\
\%\end{array}$ & $\begin{array}{c}\text { [OTID] } \\
\%\end{array}$ & [ \\
\hline Young & 12 & 88 & & 7 & 93 & \\
\hline Middle & 25 & 75 & & 15 & 85 & \\
\hline Old & 100 & 0 & & 100 & 0 & \\
\hline
\end{tabular}

\section{Conclusion}

The talks of many informants from Tirat Haifa (Palestine) are investigated to examine the speech of this group and to identify possible correlations between what is social and what is linguistic. The study shows that the Tirawi society before 1948 was distinguished from the rest of the surrounding societies, linguistically and socially. Unlike most of the surrounding societies, Tirawis have in their phonetic inventory the uvular /q variant. The key feature [q] became indissolubly linked with the Tirawis. It has become an identity feature for Tirawis whether he or she uses it or not. In Tirat Haifa, what is linguistic is merged with what is social. Kinship and linguistic competency would not be enough to make someone recognized as a genuine Tirawi by Tirawis. One cannot be labelled "genuine Tirawi" unless they acquire the complete social and linguistic role of being Tirawi. The use of the Tirawi linguistic key feature is important. But what is not less important is when and where to use it. Socially speaking, Tirawis do not use the first name and the surname inside the village to identify oneself. The first name and the father's name being preceded by the definite article al (the) are used. Outside the village, the name "Tirawi" (a name derived from the name of their village) is used as a surname.

The Tirawis show preservation to this dialect even when they settled in Jordan. This can inform us about the strong effect of the Tirawi society on them to do so. The use of this original dialect is used to achieve something beyond any linguistic aim. It aims to confirm identity, and as such helps the user of this native dialect to project himself as part of Tirawi society. In other words, appearing as "real Tirawi". Abandoning this dialect is equal to abandoning one's identity. Even the young of today, and who were born in Jordan, once they want to appear as "real Tirawis", in any Tirawi gathering, the use of these old words is seen to be the best and the fastest way to prove so. So rendering oneself real Tirawi requires the emergence of these traditional Tirawi words in the speech and the suppression of any other words from any other dialect. A high degree of Tirawi dialect is closely linked with strong resistance to any other identity rather than the Tirawi's. as such it could be said that the social meanings of the use of the Tirawi dialect "hop" from Tirat Haifa to Jordan.

\section{References}

Abdel-Jawad, H. (1981). Lexical and phonological variation in spoken Arabic in Amman. University of Pennsylvania PhD. dissertation. 
Al Khatib, M. (1988). Sociolinguistic change in an expanding urban context: a case study of Irbid city, Jordan. PhD thesis. University of Durham.

Al-Wer, E. (1991). Phonological variation in the speech of women from three urban areas in Jordan. University of Essex. $\mathrm{PhD}$ dissertation.

Amara, M., Spolsky, B., and Tushyeh, H. (1999). Sociolinguictic of socio-political Patterns In Bethlehem: preliminary studies. In Y. Suleiman (ed.), Language and Society in the Middle East and North Africa, Studies in Variation and Identity, 58-80. Surrey: Curzon Press.

Daher, J (1998). Gender In Linguistic Variation: The Variable (Q) In Damascus Arabic. In E, Benmamoun, M, Eid and N. Haeri (ed),Perspectives On Arabic Linguistics XI, 183-205. Amsterdam: Benjamins Publishing Company.

El Salman, M (1990). Tirat Haifa between 1900-1948. Irbid: Qudssya press.

Gubser, P. (1973). Politics and Change in Al-Karak, Jordan. Oxford: Oxford University Press.

Khalidi, W. (1992) (ed). All that remains: The Palestinian villages occupied and depopulated by Israel in 1948. Washington: Institute of Palestinian Studies.

Labov, W. (1966). The social stratification of English in NewYork City. Washington, DC: Center for Applied Linguistics.

Labov, W. (1972a). The study of language in its social context. In J. Pride And J. Holmes (eds.), Sociolinguistics: selected reading, 1: 180-201. Middlesex: Penguin.

Labov, W. (1972b). Sociolinguistic patterns. Philadelphia: University of Pennsylvania Press.

Labov, W. (2001). Principles of linguistic change. Vol. 2. Oxford: Blackwell.

Mesthrie, R. (2000). Clearing the ground: basic issues, concepts and approaches. In R. Mesthrie, J. Swann, A. Deumert and W. Leap (eds.), Introducing Sociolinguistics, 1-43. Edinburgh: Edinburgh University Press.

Milroy, J. and Milroy, L. (1997). Varieties and variation. In F. Coulmas (ed.), The Handbook of socio-linguistics, 1: 4764. Oxford: Blackwell.

Mulinen, G (1908). Contributions to the Knowledge of Mt. Carmel. Separate printing from the Journal of the German Palestine Society, XXX, 117-207.

Trudgill, P. (1974). The Social Differentiation of English in Norwich. Cambridge: Cambridge University Press

Walters, K. (1991). Women, men, and linguistic variation in the Arab world. In B.Comrie and M. Eid (eds.), Perspectives on Arabic linguistics III, 197-229. Amsterdam: John Benjamins Publishing Company. 